Original Research Paper

\title{
Pemanfaatan Lahan Kosong untuk Budidaya Tanaman Sayuran sebagai Nilai Tambah Ekonomi dengan Konsep Rumah Pangan Lestari di Desa Seriwe Kabupaten Lombok Timur
} \author{
Sulestra $^{5}$, Ahmad Raksun 6 \\ ${ }^{I}$ Program Studi Akuntansi Non-Reguler, Fakultas Ekonomi dan Bisnis Universitas Mataram; \\ ${ }^{2}$ Program Studi Ilmu dan Teknologi Pangan, FATEPA Universitas Mataram; \\ ${ }^{3}$ Program Studi Pendidikan Biologi, FKIP Universitas Mataram; \\ ${ }^{4}$ Program Studi Akuntansi, Fakultas Ekonomi dan Bisnis Universitas Mataram; \\ ${ }^{5}$ Program Studi Kimia, FMIPA Universitas Mataram; \\ ${ }^{6}$ Program Studi Pendidikan Biologi FKIP Universitas Mataram.
}

Adrian Putra Suhendar ${ }^{*}$, Ana Juliana ${ }^{2}$, Endah Kurnia Widaswara ${ }^{3}$, Gusti Ayu Vidya Amara ${ }^{4}$, I Nyoman

https://doi.org/10.29303/jpmpi.v3i2.1436

Sitasi: Suhendar, A. P., Juliana, A., Widaswara, A., Amara, G. A. V., Sulestra, I. N \& Raksun, A. (2022). Pemanfaatan Lahan Kosong untuk Budidaya Tanaman Sayuran sebagai Nilai Tambah Ekonomi dengan Konsep Rumah Pangan Lestari di Desa Seriwe Kabupaten Lombok Timur. Jurnal Pengabdian Magister Pendidikan IPA, 5(1)

Article history

Received: 11 Januari 2022

Revised: 11 Februari 2022

Accepted: 27 Februari 2022

*Corresponding Author:

Adrian Putra Suhendar,

Program Studi Akuntansi Non-

Reguler, Fakultas Ekonomi dan

Bisnis Universitas Mataram;

Email:

adrianputra078@gmail.com

\begin{abstract}
Desa Seriwe merupakan salah satu desa di Kecamatan Jerowaru, Kabupaten Lombok Timur Propinsi Nusa Tenggara Barat dengan jumlah penduduk lebih kurang 3.474 jiwa. Luas wilayah Desa Seriwe yaitu 15.000 Ha, terletak pada ketinggian tanah 5-20 mdpl. Hampir setiap penduduk di Desa Seriwe memiliki pekarangan yang belum dimanfatkan. Pekarangan tersebut dapat dimanfaatkan untuk budidaya tanaman sayuran sehingga dapat meningkatkan hasil pangan dan meningkatkan gizi masyarakat. Dalam upaya peningkatan kesadaran dan motivasi masyarakat untuk memanfaatkan lahan pekarangan yang kosong maka dilakukan kegiatan penyuluhan dan pembuatan green house percontohan untuk pembibitan tanaman sayuran yang dilakukan oleh mahasiswa dan dosen Universitas Mataram. Kegiatan ini diharapkan dapat memberikan pemahaman awal tentang pentingnya pertanian rumah tangga dalam pemanfaatan lahan pekarangan dengan konsep rumah pangan lestari. Dalam kegiataan ini dilakukan penyuluhan dengan metode ceramah dan demonstrasi pembuatan green house percontohan dalam pengadaan bibit tanaman sayuran. Budidaya tanaman sayuran dilakukan dengan cukup sederhana yaitu memanfaatkan pekarangan kosong untuk budidaya tanaman sayuran dengan media tanam berupa tanah yang diletakkan dalam polybag, botol bekas ataupun sampah plastik serta menggunakan kayu, bambu atau pipa sebagai rak untuk menaruh tanaman agar tersusun rapi di lahan pekarangan rumah. Kegiatan ini diharapkan dapat meningkatkan kesadaran dan motivasi masyarakat untuk memanfaatkan lahan pekarangan yang kosong sehingga dapat memenuhi kebutuhan bahan pangan khususnya bahan sayuran di era new normal ini.
\end{abstract}

Keywords: Budidaya Tanaman Sayur; Desa Seriwe; Pekarangan Kosong; Rumah Pangan Lestari.

Nusa Tenggara Barat dengan jumlah penduduk kurang lebih 3.474 jiwa. Luas wilayah Desa Seriwe yaitu $15.000 \mathrm{Ha}$ dengan ketinggian tanah 5-20 mdpl, memiliki curah hujan $1200 \mathrm{~mm}$ pertahun sehingga rata-rata suhu udara berkisar antara $20^{\circ} \mathrm{C}$ $35^{\circ} \mathrm{C}$. Tofografi wilayah Desa Seriwe meliputi 
wilayah pantai dengan dataran rendah yang bergelombang. Pemanfaatan wilayah Desa Seriwe didominasi oleh penggunaan lahan untuk budidaya tanaman jagung dan untuk wilayah pesisir pantai digunakan sebagai tempat budidaya rumput laut.

Budidaya merupakan kegiatan yang direncanakan untuk melestarikan sumber daya hayati di suatu daerah untuk diambil dan dimanfaaatkan hasil panennya. Budidaya tanaman dilakukan dalam berbagai macam kegiatan pengembangan dan pemanfaatan sumber daya alam nabati yang dilakukan oleh manusia dengan menggunakan modal, teknologi ataupun sumber daya lainnya untuk menghasilkan suatu produk yang dapat memenuhi kebutuhan manusia (PP RI No. 18 Tahun 2010 tantang Usaha Budidaya Tanaman). Jenis tanaman yang ditanam pada kegiatan budidaya tanaman ini seperti sawi hijau, pakcoy, dan bayam.

Potensi ketersediaan lahan pertanian di desa Seriwe cukup luas yaitu lahan pangan seperti penanaman jagung di lahan sawah atau perbukitan. Lahan pangan di area pesisir pantai dimanfaatkan masyarakat sebagai lahan budidaya rumput laut. Sebagian besar penduduk di Desa Seriwe memiliki lahan yang cukup luas yang dapat dimanfaatkan untuk budidaya tanaman sayuran sehingga dapat meningkatkan hasil pangan.

Lahan pekarangan milik warga masih banyak yang belum dimanfaatkan secara maksimal dan sebagian besar lahan tersebut terbengkalai dengan ditumbuhi rumput liar. Lahan pekarangan dapat dimanfaatkan untuk menanam hortikultura untuk memenuhi kebutuhan pangan dan menambah pendapatan ekonomi rumah tangga (Oktaviani, dkk., 2020). Potensi pekarangan yang begitu besar untuk dimanfaatkan masih belum disadari oleh masyarakat. Pemanfaatan pekarangan biasanya hanya untuk mengisi waktu luang saja, sehingga pengelolaan pekarangan belum dilakukan dengan optimal.

Menurut Muttaqin, dkk., (2018), pangan merupakan kebutuhan pokok manusia yang harus dipenuhi karena berhubungan dengan kelangsungan hidup manusia. Lahan pekarangan masyarakat jika dikembangkan secara optimal dapat memenuhi kebutuhan akan pangan terutama sayur-sayuran sehingga dapat mengimbangi nutrisi masyarakat yang dominan mengkonsumsi makanan hasil laut. Selain itu hasil budidaya tanaman sayuran dapat dijual untuk meningkatan pendapatan masyarakat.

Rumah Pangan Lestari (RPL) merupakan salah satu sistem budidaya tanaman pangan yang meliputi sayur- sayuran yang dapat dikembangkan dengan memanfaatkan pekarangan rumah. Budidaya sayur dengan konsep RPL ini dapat diterapkan pada pekarangan rumah agar lebih produktif serta dapat memenuhi kebutuhan pangan masyarakat. Rumah Pangan Lestari (RPL) merupakan salah satu program Badan Litbang pertanian yang bekerjasama dengan pemerintah dalam rangka mewujudkan kemandirian pangan di Indonesia (Saptana, dkk., 2013).

Berdasarkan hasil kajian Badan Litbang Pertanian, sebagaimana dilaporkan Mardiharini, (2011), bahwa perhatian terhadap pemanfaatan pekarangan masi terbatas. Akibatnya pengembangan berbagai inovasi yang terkait dengan lahan pekarangan belum mencapai sasaran seperti yang diharapkan. Sebagian besar masyarakat hanya fokus pada mata pencaharian pokoknya dan jarang memperhatikan potensi yang bisa dihasilkan dari pekarangan rumah. Belum banyak edukasi yang diterima masyarakat mengenai pemanfaatkan pekarangan kosong juga menjadi penyebab belum dimanfatkannya lahan pekarangan secara optimal.

Tujuan pelaksanaan kegiatan ini adalah agar masyarakat dapat memanfaatkan lahan pekarangan sebagai penghasil sayur-sayuran yang sehat agar ketahanan pangan pada masyarakat dapat terimbangi dan menjadi salah satu cara untuk meningkatkan ekonomi masyarakat khususnya di daerah Desa Seriwe, Kecamatan Jerowaru, kabupaten Lombok Timur, Nusa Tenggara Barat.

\section{Metode}

Kegiatan ini dilakukan oleh mahasiswa dan dosen Universitas Mataram di wilayah Desa Seriwe, Kecamatan Jerowaru, Kabupaten Lombok Timur, Provinsi Nusa Tenggara Barat. Program kerja yang dilakukan adalah budidaya tanaman sayur dengan memanfaatkan pekarangan kosong milik masyarakat menggunakan media tanah yang diletakkan di dalam polybag, botol bekas dan sampah plastik yang dilaksanakan pada tanggal 27 Desember 2021 - 10 Februari 2022 (selama 45 hari).

Metode yang digunakn dalam pelaksanaan Rumah Pangan Lestari (RPL) ini meliputi 
sosialisasi kegiatan, diskusi serta tanya jawab dan dengan melakukan demonstrasi kegiatan secara langsung kepada masyarakat. Metode sosialisasi yaitu untuk mengenalkan kegiatan yang akan dilakukan dan bertujuan untuk menambah ilmu serta wawasan kepada masyarakat sekitar terkait dengan program kerja yang kami lakukan. Selanjutnya pembuatan media tanam menggunakan polybag, botol bekas dan sampah plastik serta pembuatan green house untuk meletakkan tanaman tersebut. Ketiga yaitu penanaman bibit yang sudah disemai yang berumur 7-10 hari untuk dipindahkan kedalam media tanam. Terakhir yaitu pembagian bibit kepada masyarakat.

\section{Hasil dan Pembahasan}

\section{Pembuatan Media Tanam dan Green House}

Kegiatan ini dilakukan untuk program wajib, dengan menggunakan polybag, botol bekas atau sampah plastik untuk meletakkan tanah sebagai media tanam. Pembuatan Green House untuk menaruh tanaman agar bisa tersusun rapi. Penggunaan botol plastik dan sampah plastik juga menjadi alternatif lain pengganti polibag untuk mengurangi biaya yang akan dikeluarkan sehingga keluhan masyarakat tidak dapat melakukan budidaya karena biaya dapat diatasi. Media tanam diisi dengan tanah yang sudah dicampur dengan kotoran sapi (pupuk kompos). Kemudiaan dilakukan penanaman bibit dengan berbagai jenis tumbuhan seperti pakcoy, sawi hijau dan bayam hijau. Proses penyemaian dilakukan dengan cara mene barkan benih tanaman sayuran ke tanah yang tempatnya lembab atau nampan yang diisi dengan campuran pupuk kompos. Kemudian menaburkan sedikit tanah lagi diatasnya dan beri sedikit air hingga benih menjadi basah.

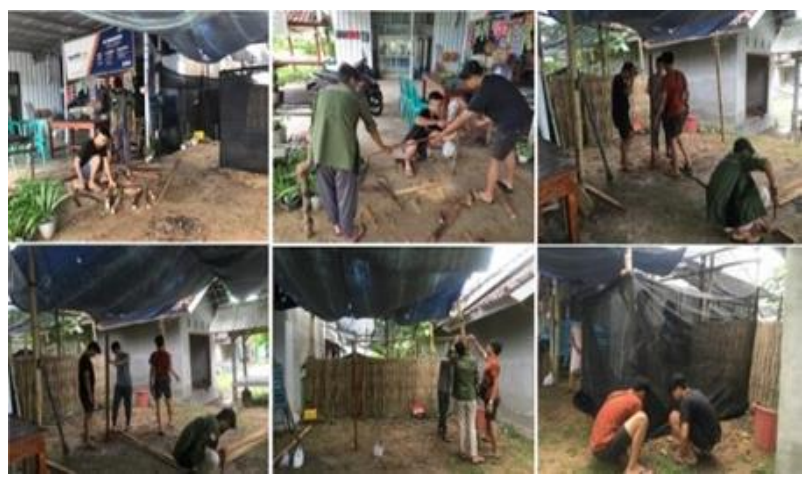

Gambar 1. Pembuatan Media Tanam dan Green House.

\section{Penanaman Bibit}

Jenis tanaman yang ditanam adalah pakcoy, sawi hijau dan bayam hijau. Bibit yang sudah disemai dan sudah berumur 7-10 hari dapat dipindah ke dalam wadah media tanam yaitu polybag, botol plastik atau sampah plastik.

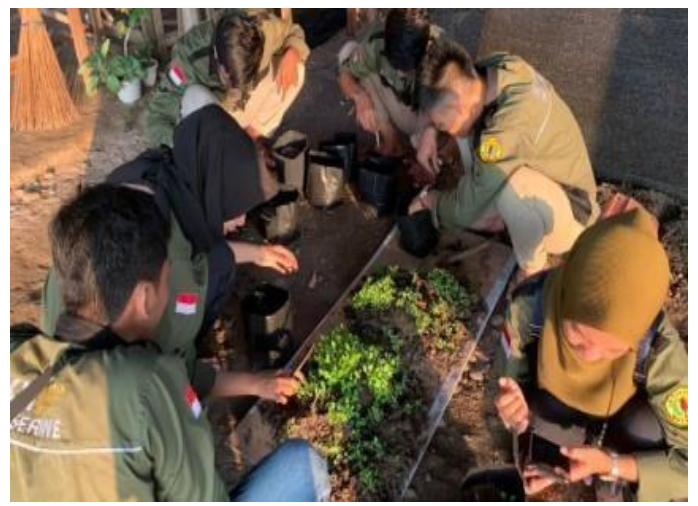

Gambar 2. Penanaman Bibit

\section{Kegiatan Penyuluhan}

Penyuluhan dilaksanakan untuk menambah wawasan dan pengetahuan masyarakat Desa Seriwe bahwa terdapat potensi yang dapat dikembangkan, baik dari segi SDA maupun SDM-nya. Penyuluhan juga dilaksanakan untuk mengatasi permasalahan yang ada di Desa Seriwe diantaranya kurangnya kesadaran masyarakat untuk memanfaatkan pekarangan rumah sebagai tempat budidaya tanaman pangan.
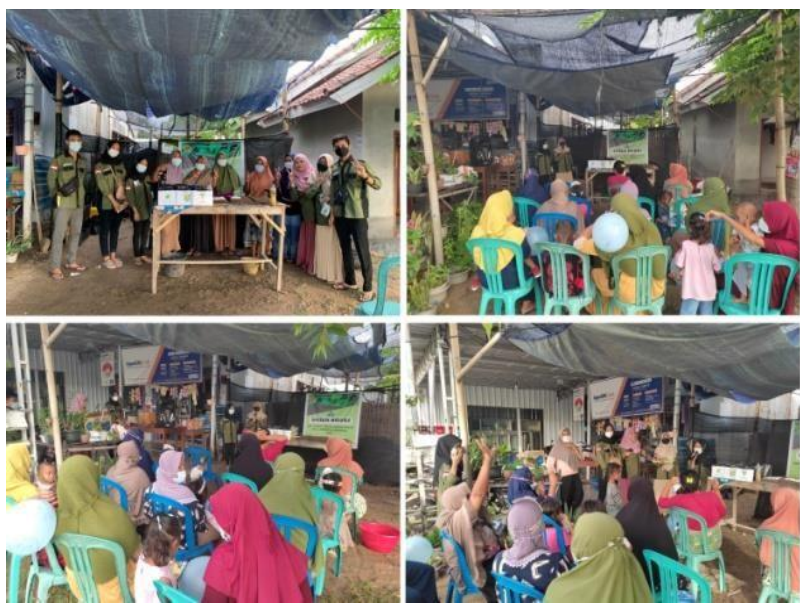

Gambar 3. Penyuluhan Pengembangan Kawasan Rumah Pangan Lestari.

Selanjutnya setelah kegiatan penyuluhan dilaksanakan pembagian bibit kepada masyarakat Desa Seriwe. Bibit yang sudah dibagikan 
diharapkan dapat diprawat oleh masyarakat dengan baik dengan pendampingan yang dilakukan ileh mahasiswa Universitas Mataram. Setelah umurnya cukup nantinya pemanenan tanaman sayuran akan dilakukan oleh masyarakat yang memelihara tanaman tersebut.

\section{Kesimpulan}

Penerapan tema Rumah Pangan Lestari (RPL) di Lingkungan Desa Seriwe, Kecamatan Jerowaru, Kabupaten Lombok Timur, Provinsi Nusa Tenggara Barat telah dilakukan dan dapat diterima oleh masyarakat setempat. Penerapan teknik budidaya sayuran dengan memanfaatkan pekarangan kosong masyarakat dengan media tanam berupa tanah yang diletakkan dalam polybag, botol bekas, ataupun sampah plastik dan juga kayu, bambu atau pipa sebagai tempat menaruh tanaman merupakan salah satu solusi ketahanan pangan di era new normal.

Mengingat pentingnya sayuran bagi

kesehatan manusia, kami sangat mengharapkan dukungan dari masyarakat terutama remaja serta mahasiswa KKN selanjutnya untuk meneruskan kegiatan ini terkait dengan keberlangsungan program kerja budidaya sayur organik yang nantinya dikembangkan oleh masyarakat agar dapat dijadikan solusi ketahanan pangan masyarakat.

\section{Ucapan Terima Kasih}

Terimakasih yang sebesar-besarnya kami sampaikan kepada Bapak Rektor dan Ketua LPPM Universitas Mataram yang telah memfasilitasi kegiatan kami. Ucapan terima kasih juga penulis sampaikan kepada Kepala Desa Seriwe, Kecamatan Jerowaru, Kabupaten Lombok Timur atas dukungan, penerimaan dan izin yang diberikan kepada mahasiswa KKN Tematik Universitas Mataram untuk menerapkan penerapan tema Rumah Pangan Lestari (RPL) di Lingkungan Desa Seriwe.

\section{Daftar Pustaka}

Mardiharini, M. 2011. Model Kawasan Rumah Pangan Lestari dari Pengembangannya ke Seluruh
Provinsi di Indonesia. Warta Penelitian dan Pengembangan Pertanian. 33 (6) : 3-5.

Muttaqin, Z., D.S. Sari, dan R. Purbasari. 2018. Pemanfaatan Lahan Kosong Mengupayakan Ketahanan Pangan Global dalam Keseharian Masyarakat Lokal di RW 12 Desa Sayang, Jatinangor, Sumedang. Prosiding Penelitian dan Pengabdian Kepada Masyarakat. 5 (3) : 237-250

Oktaviani, A.D., N.N.P. Ullayah, T.S Yuliani, M.S. Rahayu, I. Lubis dan F. Nurul. 2020. Pemanfaatan Lahan Pekarangan untuk Memenuhi Kebutuhan Keluarga di Desa Cintalaksana, Kecamatan Tegalwaru, Kabupaten Karawang. Jurnal Pusat Inovasi Masyarakat. 2 (4) : 535-539.

Peraturan Pemerintah RI No. 18 Tahun 2010. Tentang Buddidaya Tanaman. Bandung. Citra Umbara.

Saptana, Sunarsih, dan S. Friyatno. 2013. Prospek Model- Kawasan Rumah Pangan Lestari (MKRPL) dan Replikasi Pengembangan KRPL. Forum Penelitian Agro Ekonomi. 31 (1) :67-87. 